\title{
Estándares Básicos para los Laboratorios de Pruebas de Paternidad en Colombia, 2005
}

\author{
Alejandro Giraldo , Antonio Bermúdez², Magda Jiménez ${ }^{3}$ y Rocio Lizarazu ${ }^{4}$ \\ 1 Médico Genetista. Especialista en Estadística. M. Sc. Public Health. Director Fundación Gillow. \\ Delegado de la Asociación Colombiana de Sociedades Científicas, ante la Comisión de Acreditación y \\ Vigilancia de los Laboratorios que Practican las Pruebas de paternidad o maternidad con marcadores \\ genéticos de ADN. Departamento de Medicina Interna. Universidad Nacional de Colombia. \\ E-Mail: agiraldori@unal.edu.co \\ ${ }^{2}$ Médico. M. Sc. Bioquímica. Red Nacional de Laboratorios del Instituto Nacional de Salud. E-Mail: \\ abermudezj@ins.gov.co \\ 3 Química. Ph. D. Instituto Colombiano de Medicina Legal y Ciencias Forenses. E-Mail: \\ mgdjimenezs@yahoo.com \\ 4 Bacterióloga. M. Sc. Biología (Genética). Instituto Colombiano de Medicina Legal y Ciencias \\ Forenses. E-Mail: rocio_lizarazo_q@yahoo.com
}

Recibido 13 Diciembre 2005/Enviado para Modificación 15 Abril 2005/Aceptado 15 Junio 2006

\section{RESUMEN}

La "Comisión de Acreditación y Vigilancia de los Laboratorios que practican las pruebas de paternidad o maternidad con marcadores genéticos de ADN", creada por la Ley 721 de 2001, constituyó una Sub-comisión para revisar las normas colombianas sobre los Estándares Básicos Requeridos en los Laboratorios de Pruebas de Paternidad, para que específicamente recomendara los aspectos técnicos pertinentes en Colombia, tomando como referente permanente la Norma ISO 17025. En este documento se consignan estas recomendaciones para Colombia.

Palabras Clave: Prueba, paternidad, estándares, laboratorios, ISO 17025 (fuente: DeCS, BIREME).

\section{ABSTRACT \\ Basic standards for Colombian paternity testing laboratories, 2005}

The Commission for Accreditation and Surveillance of Laboratories Practicing DNA Paternity Tests (created by the Colombian Law 721/2001) set up a sub-commission to review the current basic Colombian standards required for paternity testing laboratories and make specific recommendations re the pertinent technical aspects in Colombia, taking ISO 17025 as current reference. This document contains such recommendations for Colombia. 
Key Words: Paternity testing, standards, laboratory, ISO 17025 (source: $\mathrm{MeSH}, \mathrm{NLM}$ )

$\mathrm{L}$ a "Comisión de Acreditación y Vigilancia de los Laboratorios que Practican las Pruebas de paternidad o maternidad con marcadores genéticos de ADN" aprobó mediante la Resolución No 001 del 3 de Junio de 2004 el documento publicado en junio de 2002 por el ICBF, denominado "Recomendaciones de Estándares Básicos Requeridos en los Laboratorios de Pruebas de Paternidad" (1) para que oficialmente se tomara como guía para los laboratorios que realizan estas pruebas. Este documento se basó en su totalidad en una versión en inglés, de la norma internacional ISO 17025, al cual se le agregaron aplicaciones específicas para los laboratorios que manejan $\mathrm{ADN}$, antes de que existiera en nuestro país la versión oficial de la misma, como Norma Técnica Colombiana, NTC-ISO-IEC 17025 (2). Debido a ello, el documento en mención contiene algunos términos discrepantes con la traducción oficial y repite la totalidad de las generalidades de la Norma. Así mismo, contiene los criterios de la época recomendados por la Sociedad Internacional de Genética Forense, los cuales posteriormente fueron precisados por esta misma Sociedad, acogiendo así mismo la Norma ISO 17025 (3).

Por esta razón la Comisión constituyó un Sub comité ad hoc para revisar el documento del ICBF antes mencionado, de manera tal que la versión oficial NTC-ISO-IEC 17025 (2), sea la base para las normas de estos laboratorios y se propusiera un nuevo documento con únicamente lo concerniente a los aspectos técnicos y a la reglamentación que sobre éstos ha desarrollado la Comisión, de manera semejante a lo desarrollado por la Comisión de Pruebas de Paternidad de la Sociedad Internacional de genética Forense (3). Se han tenido en cuentan así mismo las versiones pertinentes y más recientes del Grupo Científico de Trabajo en Métodos de Análisis con ADN (Scientific Working Group on DNA Analysis Methods: SWGDAM) $(4,5)$

Tal como lo establece la Ley 721 de 2001 (6), los laboratorios deben primero cumplir con las disposiciones legales contenidas en el decreto 2309, por medio del cual el Gobierno establece el Sistema de Garantía de Calidad de la Atención en Salud, en especial a lo pertinente contenido en el artículo $7^{\circ}$ y siguientes, denominado "Sistema Único de Habilitación” (7).

A continuación se indican los requisitos técnicos que deben cumplir los laboratorios que realicen pruebas de filiación en el país, indicando el correspondiente numeral de la norma ISO 17025 que aplica para cada requisito. 
Debe quedar claro que los numerales no contenidos en este documento ( 1 a 4 y algunos sub-numerales del 5) son los correspondientes a la versión oficial NTC-ISO-IEC 17025 (2).

\section{REQUISITOS TÉCNICOS}

\subsection{Personal}

\subsubsection{Director del Laboratorio:}

"Tener mínimo título en áreas de ciencias biologías, químicas o medicina. Debe tener un postgrado en áreas afines. Debe tener experiencia de mínimo tres años en pruebas de filiación y haber participado en mínimo 100 pruebas de filiación o experiencia de dos años en la aplicación de métodos de biología molecular en genética forenses, debidamente documentadas.

\subsubsection{Analistas:}

"Titulo profesional en áreas de ciencias biologías, químicas o medicina, debe tener experiencia, de mínimo un año en pruebas de paternidad o experiencia de un año en la aplicación de métodos de biología molecular, debidamente documentado.

\subsection{Instalaciones y condiciones ambientales}

El laboratorio debe contar con área administrativa la cual debe estar separada del área de laboratorio donde se procesan las muestras y comprende: recepción, sala de espera, baños, archivo de registros y toma de muestras.

Para minimizar el problema de contaminación, el área de laboratorio donde se procesan las muestras deberá tener una organización que asegure una estricta separación física permanente: área extracción, área de montaje de PCR, área de amplificación (manejo, análisis y almacenamiento de productos de PCR), cada una de estas áreas deberá contar con sitios de preparación y de almacenamiento de los reactivos de uso exclusivo.

\subsection{Métodos de ensayo y calibración y validación de métodos.}

\subsubsection{Generalidades:}

Este documento incluye lo relacionado con la amplificación de ADN utilizando la reacción en cadena de la polimerasa (PCR) de STRs autosómicos que es la metodología utilizada actualmente en los laboratorios Colombianos que realizan pruebas de filiación y sus resultados se ajustan a un cálculo probabilístico de acuerdo con lo exigido por la ley 721 del 2001. 
El uso de nuevas tecnologías implicará, una revisión del tema para generar requisitos técnicos acordes a los avances científicos y tecnológicos del momento.

Amplificación de ADN de repeticiones cortas en tándem (STR) mediante la reacción en cadena de la polimerasa de STR autosómicos:

- Utilizar blanco de extracción, control positivo y negativo de PCR

- Contar con un método de cuantificación de ADN, excepto para los laboratorios que utilizan soporte FTA para la recolección de las muestras y por el método de extracción utilizado el ADN queda adherido al soporte.

Análisis de resultados:

- Cuando se utiliza software para el análisis de la información, definir la mínima y máxima intensidad de las señales que se tomen como alelos.

- Los laboratorios que no cuentan con software para el análisis de la información deben establecer criterios para la evaluación visual de las imágenes de los geles.

- Tener criterios para la interpretación de los controles utilizados en las diferentes etapas de análisis.

- Contar con criterios para la interpretación de resultados cuando los controles no sean de la calidad esperada.

Designación de los alelos:

- Utilizar un método estándar de nomenclatura de los alelos (DNA Index System, CODIS, ISFG).

- Para alelos que no se encuentran en la escalera alélica consultar en la literatura científica y repetir la amplificación para confirmar que no se trate de artefactos.

- Contar con criterios para la interpretación de artefactos.

Interpretación probabilística:

Los laboratorios deben emplear las frecuencias alélicas de muestreos genéticos de población colombiana, publicadas en revistas indexadas. Para los marcadores donde no se cuente con muestreos genéticos poblacionales de población Colombiana podrán utilizar las frecuencias poblacionales disponibles para hispanos y contenidas en los insertos de los kits comerciales.

- Las frecuencias de la tasa de mutación de los sistemas utilizados deben estar documentadas y usadas adecuadamente. 
- Definir las frecuencias mínimas a utilizar

- Utilizar el cálculo de probabilidad de acuerdo a la situación en estudio: trío completo, ausencia de uno de los progenitores, paternidad con abuelos u otros familiares.

- Los marcadores genéticos utilizados no deben estar ligados.

5.4.2. Selección de métodos. El laboratorio debe utilizar sistemas genéticos para los cuales haya pruebas interlaboratoriales disponibles.

5.4.5. Validación de Métodos. Los estudios de validación de un nuevo marcador o marcadores (loci) genéticos deben incluir:

- Estudios de especificidad de especie para el locus propuesto

- Estudios para determinación de herencia mediante estudios con familias

- Estudios de sensibilidad

- Estabilidad

- Reproducibilidad

- Estudios poblacionales

- Estudios de precisión y exactitud

- Optimización de la reacción en cadena de la polimerasa (PCR) de las condiciones de termociclado, componentes de la reacción, amplificación preferencial, efectos de coamplificación, uso de controles negativo y positivo.

\subsubsection{Cálculo de la incertidumbre de medición:}

5.4.5.2. Los laboratorios de ensayo deben contar con procedimientos para el cálculo de incertidumbre de la medición. Para la realización de las pruebas genéticas de filiación se desarrollan diferentes procedimientos y en cada uno de ellos se emplean controles de aceptación o no, los cuales eliminan todos aquellos factores de incertidumbre que pueden afectar el resultado.

Por lo tanto el laboratorio describirá los controles que utiliza en los procesos de tal forma que le permitan aceptar o rechazar los resultados en cada etapa.

Aquellos laboratorios que por la naturaleza de las técnicas empleadas consideren necesario la realización del cálculo de la incertidumbre, deberán practicarla y demostrar cómo ésta se aplica a los resultados de las pruebas de filiación. 


\subsubsection{Control de datos}

Todos los cálculos realizados en forma manual o con ayuda de algún software deberán ser revisados, en la etapa de revisión del informe, por el director del laboratorio o la persona que el asigne.

\subsection{Equipo}

Debe asignarse equipos para usar exclusivamente en cada una de las áreas pre y post PCR, con el fin de evitar contaminación con producto amplificado.

\subsection{Muestreo}

En recolección de muestras:

- El laboratorio debe contar con procedimientos para toma de muestras de sangre y frotis bucal.

- El lugar donde se tome la muestra deberá contar con área de espera, área de registro y área de toma de muestras, que garanticen privacidad en las etapas de registro y toma de muestras.

Para la toma de muestras es requisito indispensable:

- La asistencia simultánea de todas las personas relacionadas, a excepción de los casos en donde la autoridad ha solicitado la toma de muestras a las partes en diferente sitio.

- La asistencia del menor con la presencia de quien legalmente lo represente.

- El pleno conocimiento del alcance y finalidad del examen por parte del hijo, en la medida en que este tenga capacidad para esto.

- Que las partes no estén sometidas a engaño o coerción.

- Obtener el consentimiento informado de cada una de las personas, antes de la toma de la muestra y en el caso del menor, de quien legalmente lo represente.

El laboratorio debe verificar la identidad de las personas a las cuales se les toma la muestra, para lo cual deben:

- Tomar fotografía: Realizar el registro fotográfico del grupo conformado por las partes incluidas en el proceso con las siguientes especificaciones: Blanco y negro o a color, de frente, de medio cuerpo (la cintura para arriba) y que quede en un lugar visible el código asignado al caso por el laboratorio.

- Tomar huellas dactilares del dedo índice derecho. 
- Fotocopia del documento de identidad, en caso de no tenerlo tomar huella decadactilar.

El laboratorio debe diligenciar para cada caso el "Registro de caso y autorización para la toma de muestras-Consentimiento Informado", utilizando el formato del Anexo.

Rotulación de las muestras

Cada muestra deberá contener un rótulo con la siguiente información:

- Código único de la muestra asignado por el laboratorio

- Fecha de toma de la muestra

- Nombre de la persona a la que se tomó la muestra

- Iniciales de la persona que realizó la toma de la muestra.

5.8 Manejo de elementos de ensayo y calibración

La cadena de custodia permite garantizar la autenticidad de las muestras. Esta permite asegurar las características originales de las muestras desde la recolección (toma), embalaje, transporte, análisis, almacenamiento y disponibilidad final de éstas. Quien entrega y quien recibe la muestra, debe verificar:

- El embalaje.

- El contenido.

- Qué el rótulo de la muestra no presente tachones o enmendaduras.

- Hacer el registro de traspaso correspondiente en el formato de cadena de custodia.

- En caso de detectarse alteraciones en la rotulación o embalaje comunicarlas enseguida al jefe inmediato y dejar constancia escrita en el formato de cadena de custodia y si es posible fijar fotográficamente las alteraciones.

- Quien entrega y quien reciba debe conocer las inconsistencias detectadas.

- Si las inconsistencias no son aclaradas adecuadamente solicitar nueva toma de muestras, para descartar confusiones de las muestras.

5.8.1. Si el laboratorio requiere utilizar las muestras como material de referencia, muestreos poblacionales, en investigaciones científicas debe solicitar autorización por escrito al usuario durante la toma de muestra.

5.9. Aseguramiento de la calidad de los resultados de ensayos y calibración 
- El laboratorio debe incluir blanco de extracción cada vez que realice este procedimiento.

- El laboratorio debe incluir controles positivo y negativo en cada montaje de PCR.

- Llevar el blanco de extracción y los controles de PCR hasta tipificación.

- El laboratorio debe utilizar e incluir escaleras alélicas secuenciadas y estándar

interno, en todos los montajes de geles o corridos en equipos de electroforesis automatizados.

- Para tipificación manual en geles colocar escaleras alélicas cada seis muestras.

- En casos de exclusión de la paternidad, repetir el procesamiento de las muestras del padre y del hijo (a) desde la extracción, para confirmar las exclusiones.

- En caso de exclusiones de la paternidad se deben encontrar mínimo tres exclusiones en diferentes sistemas genéticos estudiados.

- En los casos donde se requiere reconstruir el perfil genético del presunto padre o madre a partir del estudio de muestras de los familiares mas cercanos biológicamente, dada la complejidad de estos casos (degradación del ADN de la muestra, familiares no informativos), no siempre se puede lograr las probabilidades de paternidad o el número de exclusiones según la ley 721 del 2001.

- Confirmar las exclusiones aisladas, para lo cual se debe repetir el proceso desde la extracción de la muestra y estudiar el mayor número de marcadores disponibles para confirmar que es realmente una exclusión aislada.

- El director del laboratorio o la persona que asigne (diferente a las que participaron en la realización de la prueba), debe revisar antes de enviar el informe de resultados, de cada uno de los casos a la autoridad. De esta revisión debe quedar registro:

o Los registros de cada caso

o La tipificación de las muestras a partir de las imágenes de los geles o los electroferogramas.

o Los controles y blancos.

o Los cálculos probabilísticos

o Interpretación de resultados

o Los informes de resultados 
- El laboratorio debe participar en mínimo una prueba interlaboratorial anual y tomar los correctivos inmediatos en caso de obtener resultados no consensuados.

Conflicto de intereses. Los autores declaran que no tienen intereses de ningún tipo con las empresas comerciales que puedan beneficiarse de la presente publicación

Agradecimientos. Los autores agradecen a los profesionales, de la mayoría de los laboratorios públicos y privados que practican pruebas de paternidad, que opinaron sobre el presente documento.

\section{REFERENCIAS}

1. Instituto Colombiano de Bienestar Familiar (ICBF). Recomendaciones de Estándares Básicos Requeridos en los Laboratorios de Pruebas de Paternidad. Bogotá: Taller de Publicaciones ICBF; 2002.

2. Instituto Colombiano de Normas Técnicas y Certificación (ICONTEC). Norma Técnica Colombiana NTC-ISO-IEC 17025. Requisitos Generales de Competencia de Laboratorios de Ensayo y Calibración. 2001-04-18. Reaprobado 2002-07-17. Reeditado 2002-08-05.

3. Morling N, Allen RW, Carracedo A, Geada H, Guidet F, Hallenberg C, Martin W, Mayr WR, Olaisen B, Pascali VL, Schneide PM. Paternity Testing Commission of the International Society of Forensic Genetics: recommendations on genetic investigations in paternity cases. Forensic Science International 2002;129:148-157.

4. Scientific Working Group on DNA Analysis Methods (SWGDAM). Short Tandem Repeat (STR) interpretation Guidelines [Internet]. Forensic Sci Commun 2000 2:3 Disponible en: http://www.fbi.gov/hq/lab/fsc/backissu/ july2000. Consultado: julio 19 de 2005.

5. Scientific Working Group on DNA Analysis Methods (SWGDAM). Revised Validation Guidelines, Forensic Science Communications. 2004 6:3 Disponible en: http://www.fbi.gov/hq/lab/fsc/backissu/ july2004. Consultado: julio 19 de 2005.

6. República de Colombia. Ley 721 de 2001 (diciembre 24). Por medio de la cual se modifica la Ley 75 de 1968. Diario Oficial No 44.661, de 29 de diciembre de 2001.

7. Ministerio de Salud de la República de Colombia Decreto 2309 del 15 de octubre de 2002. Diario Oficial No 44967 de 17 de octubre de 2002. 